


\title{
Los filósofos del Quijote
}

\section{The Quixote Philosophers}

\author{
Jaime Vilarroig Martín \\ Universidad CEU Cardenal Herrera, España \\ jaime.vilarroig@uch.ceu.es
}

Carlos Araya Cerda Universidad Playa Ancha, Chile arayacerda.carlos@gmail.com

Resumen: El trabajo se propone establecer las raíces filosóficas del Quijote por medio de tres estrategias: en primer lugar, buscando el nombre de filósofos relevantes en la obra (Sócrates, Platón, Aristóteles); en segundo lugar, explicitando las referencias a la filosofía escolástica que aparecen en la obra, relativas a la epistemología, la lógica, la metafísica, la teología racional, la antropología, la ética, la política y la estética; por último, presentando los textos filosóficos de referencia que Cervantes poseería en su biblioteca personal, a partir del trabajo de Eisenberg, y dividiendo las influencias en filosofía del amor, filosofía moral y política, filosofía estética, filosofía popular o paremiología y misceláneas.

Palabras claves: Filósofos, Cervantes, Quijote, Renacimiento, Filosofía Escolástica.

Abstract: This paper tries to establish the philosophical roots of Don Quixote, using three different strategies. Firstly, looking for the names of relevant philosophers in Cervantes' work (Socrates, Plato, Aristotle), 
with a rather null result. Secondly, bringing to light the abundant references to scholastic philosophy that appear in Cervantes' work, related to epistemology, logic, metaphysics, rational theology, anthropology, ethics, politics and aesthetics. Thirdly, presenting the philosophical reference texts that Cervantes would surely possess in his personal library, based on Eisenberg's work and dividing the influences on the philosophy of love, moral and political philosophy, popular philosophy or paremiology and miscellaneous.

Keywords: Philosophers, Cervantes, Don Quixote, Renaissance, Scholastic Philosophy.

Recibido: I enero de 2020

Aceptado: I 8 de julio de 2020 https://dx.doi.org/IO.I 5 I74/rv.vi3i28.5I4

\section{Preámbulo}

U

n estudio sobre la presencia de filósofos en el Quijote requiere varias aclaraciones previas. En primer lugar, se da por sentado qué es un filósofo y, en consecuencia, qué es la filosofía. Pero la filosofía siempre ha sido un saber que se busca (Aristóteles, Metafísica, A, II) y cuya definición resulta problemática. Una definición mínima de filosofía sería aquella que entiende esta como una actividad de las personas donde lo esencial es el radical cuestionar y el tentativo responder. Además, esta actividad es aquella de las que se hacen por sí mismas (frui y no uti), como le ocurre también a la literatura. Tanto la literatura como la filosofía se practica por sí misma, sin buscar utilidad ulterior. Y en esto hallamos un punto de encuentro entre la filosofía y la literatura, tan estrechamente unidas en la filosofía española en general y en Cervantes en parti- 
cular, quien sin ser filósofo escribió obras dignas de ser comentadas filosóficamente.

Un trabajo de este tipo presupone, además, que ya se conoce el Quijote y que se manifiesta interés por la filosofía española. Lo primero es obvio; lo segundo problemático porque, si difícil es ponerse de acuerdo sobre qué es filosofía, mucho más complejo será ponerse de acuerdo sobre qué se entiende por filosofía española. Ateniéndonos a una definición de mínimos, diríamos que entendemos por filosofía española el intento que realiza el hombre de pensarse y decirse a sí mismo en lengua castellana. Cada lengua (aunque los "idiomas" no dejen de ser meros flatus vocis) conlleva una experiencia del mundo que merece la pena no dejar perder. En la línea de Unamuno, filosofía es filología (Unamuno, 1967: 291). Y esto es válido, no solo para las ideas propias forjadas en una lengua propia, sino también para las ideas ajenas interpretadas por la lengua propia; porque no siempre el traductor es un traidor (a pesar de la aguda observación del cura en el donoso escrutinio, a propósito de Ariosto, en Quijote, I, 6), ${ }^{1 *}$ sino que a veces la traducción puede superar en claridad al original.

El tercer supuesto es que el intento mismo de lo que aquí se pretende va a tener algún sentido. ¿En qué consiste este empeño? En rastrear las influencias filosóficas del Quijote. ¿Para qué sirve esto? Para comprender mejor el texto porque para entender algo hay que ver de dónde procede (Gadamer, 1999: 415 y ss.). Además entenderemos mejor las repercusiones filosóficas que ha tenido la obra. Pero, ¿para qué se busca comprender mejor el Quijote? Decía Kundera que la única moral de la novela es el conocimiento (Kundera, 1987: 16). Entender una obra de arte (sea novela, cuadro o sinfonía) es conocerse mejor; y el conocimiento de sí

${ }^{1 *}$ Citamos la parte en romano y capítulo en arábigo, para que sea más fácilmente localizable la cita desde cualquier edición. 
mismo determina directamente lo que hacemos con nuestra vida. Alguien podría objetar que entonces basta con leer el Quijote para "comprenderme mejor", que no hace falta ir ni a los precedentes de la obra ni a las interpretaciones que ha suscitado. Pero a quien tal objeción hiciera habría que recodarle que la comprensión de algo presenta estructura necesariamente circular (Heidegger, 2009: $\$ 32)$ y despreciar esto es autolimitarse voluntariamente en cuanto a posibilidades de interpretación de una obra se refiere.

La expresión filosofía del Quijote se puede entender de muchas maneras. Por un lado podríamos tomar a Cervantes como filósofo, que pretendió ofrecernos con el Quijote ideas altamente filosóficas. Por ejemplo, si en nuestros días Levinás (2000) ha contrapuesto las figuras de Ulises (héroe que regresa a la patria de la cual partió, hacia el pasado) y de Abraham (héroe que sale de su patria hacia un futuro incierto), podríamos encontrar en el Quijote reunidas ambas tendencias de lo humano: el caballero de la triste figura salió cual nuevo Abraham hacia un futuro incierto, aunque al final de cada una de sus salidas regrese contra su voluntad a la tierra de la que salió, cual Ulises forzado. Otra manera de hablar de la filosofía del Quijote sería intentar identificar los sistemas o filósofos que le influyen, bien directamente, bien indirectamente. Si la filosofía es la máxima conciencia que una época cobra de sí (Hegel), esto se verá reflejado en las obras literarias de dicha época. Habría una tercera manera más humilde de exprimir la filosofía del Quijote, y sería la de ir en busca de ideas y reflexiones contenidas en el Quijote como "filosofía disuelta" en su obra (Rubio, 1943: 13 y ss.), como reflejo de la época y de la mentalidad del autor.

Algo habrá que decir sobre el problema de la interpretación del Quijote, puesto que afecta nuestro intento. En efecto, se trata de un asunto decisivo en este ejercicio porque el conflicto de las interpretaciones con esta obra cervantina es especialmente complicado al estar continuamente moviéndonos entre la realidad y 
la interpretación. Por un lado está Alonso Quijano el bueno (al que podríamos llamar el protagonista real) y por otro lado está el Caballero de la Triste Figura, don Quijote de la Mancha (al que podríamos llamar el protagonista ideado por el protagonista real). Además de esto, por un lado, tenemos el Quijote de la interpretación paródica original que salió de la mente de Cervantes (hermenéutica del autor) y, por otro, tenemos al Quijote que la crítica ha querido ver (hermenéutica de la recepción). Ante tal algarabía, optamos por un corte limpio del nudo gordiano y nos encomendamos al texto mismo (hermenéutica del texto) según la sugerencia de Ricoeur (2017: 29 y ss.), convencidos de que si bien las otras dos hermenéuticas son necesarias, el texto mismo, la obra, marca un criterio canónico que es ilegítimo ignorar.

Sirva esta prevención para evitar algunos caminos que nos parecen impracticables y vedados en esta suerte de estudios. Partir de apriorismos y tópicos sobre una época concreta y su filosofía, para después encontrar ejemplos de ello en el Quijote es un camino demasiado fácil, pero seguramente improductivo. También aquí, para ser serios, deberíamos dejar de lado el intento de verificar teorías y hablar, más bien, en términos de falsabilidad, como querría Karl Popper (1980: 75 y ss.). No es que esté mal lanzar hipótesis sobre sistemas filosóficos que pudieron influir en Cervantes; pero si estos sistemas filosóficos no pasan de lo tópico y encima nos preocupamos solo por verificar nuestra propia teoría, el intento será vano.

Pongamos un ejemplo de este mal proceder. Según el krausista Federico de Castro, en la época de Cervantes dos escuelas filosóficas se disputaban el protagonismo, oponiéndose férreamente a la anquilosada escolástica (López Calle, 2013: 6). El naturalismo aristotelista y experimentalista tendría sus máximos representantes en Huarte de San Juan u Oliva Sabuco. El misticismo platónico e idealista tendría sus representantes en los grandes místicos carme- 
litas. Pues bien, estas dos tendencias fueron armonizadas académicamente por Fox Morcillo (Aristóteles-Platón) huyendo de la escolástica, y literariamente por Cervantes (Sancho-Quijote), huyendo igualmente de la escolástica. Este seductor esquema interpretativo es tan arquitectónicamente limpio como filosóficamente inútil. Ni había solo dos tendencias en el Renacimiento español, ni había tal antiescolasticismo, ni mucho menos el Quijote fue el representante literario de todo ello. Nosotros intentaremos ir más modestamente al texto, para que sea él mismo quien nos marque las pautas.

Así pues, vamos a buscar en el texto mismo filósofos y sistemas filosóficos (predominantemente del ámbito en el que se movió el autor), a fin de comprender mejor la obra y comprendernos mejor. Para ello haremos tres intentos sucesivos: primero intentaremos rastrear la presencia de "grandes filósofos" en el Quijote. Tras constatar la práctica ausencia de referencias directas a ningún gran pensador, en un segundo momento nos retrotraeremos a las fuentes que posiblemente configuraron la mente del joven Cervantes en su época de formación: el humanismo y la escolástica. En tercer lugar acudiremos a las obras que el propio Cervantes leyó y en las que pudo encontrar materia filosófica más que suficiente para escribir su inmortal obra.

\section{Primer intento: los grandes filósofos}

El primer intento para rastrear fuentes filosóficas en el Quijote es bien sencillo: busquemos nombres de filósofos ilustres que aparezcan en el Quijote. Pero procediendo así el resultado es decepcionante. Si buscamos en el Quijote a los filósofos que la historia ha considerado más influyentes, la tríada griega compuesta por Sócrates, Platón o Aristóteles, pronto nos damos cuenta que las alusiones son escasísimas. Y si esto pasa con los gigantes del pensamiento, qué no pasará con las figuras menores. Así que da la 
impresión de que la cultura filosófica de Cervantes fue extremadamente menguada (y conste que esto solo puede ser entendido peyorativamente por quien considerase que la filosofía "académica" es la única forma legítima e interesante de hacer filosofía).

Sócrates no es mencionado literalmente, pero aparece una clarísima referencia a él en la obra. Cuando don Quijote le da los consejos a Sancho para ir a gobernar la Ínsula Barataria lo primero que le recomienda es que tenga temor de Dios pues es el inicio de la sabiduría y el gobernante que viva según esta virtud se verá libre de la tentación de convertirse en un tirano. Pero el segundo consejo, de todos conocido, es: "has de poner los ojos en quien eres, procurando conocerte a ti mismo, que es el más difícil conocimiento que puede imaginarse" (Quijote, II, 42). Esta idea de indudable raigambre socrática podría conocerla Cervantes por ser un tópico humanista ampliamente repetido, muy reforzado por la literatura mística de su época, que también conoció el autor del Quijote, y entre cuyos temas favoritos iniciales siempre había alguno dedicado "al conocimiento de sí mismo" como primer peldańo en el camino hacia la unión mística con Dios (p. ej., Diego de Estella, 1574: Parte III, Cap. xx).

Si bien no corresponde a una referencia directa, el socratismo cristiano en la obra ubica en su lugar más pertinente a los dos protagonistas -Don Quijote y Alonso Quijano-, y puede entenderse como concreción de lo antropológico y lo social contenido en el segundo de los consejos que entrega el hidalgo a su escudero para que este asuma el rol de gobernador; además, sintetiza en su dialéctica los rasgos renacentistas y barrocos (Ruiz Fernández, 2014). Esta dialéctica es una constante desde el primero hasta el último capítulo de la obra, y en todos adquiere similar relevancia, pues permite que la obra continúe, aventura tras aventura. 
Lo que verdaderamente importa en Don Quijote es cómo se tocan las personas, cómo los sujetos interactúan, y cómo la experiencia del encuentro tiene como momento central un intercambio verbal. Allí queda patente que no se trata de una sola verdad, sino que de muchas verdades. Para Cervantes, todos los verosímiles se legitiman. Y aunque Don Quijote es un discurso central acerca de la vida como aventura, sin embargo, después de él, la vida humana será entendida como proceso (Jofré, 2016).

Según esta prevención, el elemento narrativo que articula y permite que la ficción avance es el diálogo entre los personajes, y en este existe una dialéctica que determinará influencias, contrariedades, acuerdos y variaciones en los caracteres representados. Valga en este momento una aclaración de lo expuesto en el párrafo anterior, para justificar con ella la mención de los protagonistas: Sancho aparecería, al igual que Dulcinea, como necesidad del propósito caballeresco elegido por el personaje, quien conserva reductos de la identidad que es restituida hacia la conclusión de la obra y de su obra, de acuerdo con su voluntad. De este modo, mediante las interacciones entre caballero y escudero, se genera un intercambio que, por su naturaleza constructiva, muestra en sus mecanismos expresivos, la posibilidad de actuación del diálogo con rasgos de socratismo.

Platón no tiene mejor fortuna que Sócrates, puesto que tampoco aparece nombrado directamente en el Quijote. Las teorías del amor platónico más serias que indudablemente están en Cervantes vendrán seguramente a través de los diálogos de León Hebreo, como comentaremos luego. Sin embargo, lo que Cervantes entiende por amor platónico no es más técnico que lo que una persona sin formación filosófica pueda entender. Cuando don Quijote quiere dictar su carta a Sancho para Dulcinea, y cae en la cuenta de que Sancho no sabe escribir, le dice: “...a lo que yo me sé acordar, 
Dulcinea no sabe escribir ni leer, y en toda su vida ha visto letra mía ni carta mía, porque mis amores y los suyos han sido siempre platónicos, sin extenderse a más que a un honesto mirar" (Quijote, I, 25). Por donde se echa de ver todo lo que habría leído Cervantes de Platón: nada.

Aristóteles corre mejor suerte, pero solo porque su nombre aparece directamente en el Quijote, aunque no es seguro que Cervantes lo conociera mucho mejor que a Platón: las menciones que aparecen del Estagirita no tienen que ver con ninguna teoría filosófica concreta sino con los tópicos al alcance de cualquier humanista de la época. Así, hablándonos de los abstrusos discursos que aparecían en los libros de caballerías, nos dice el autor de don Quijote que "con estas razones perdía el pobre caballero el juicio, y desvelábase por entenderlas y desentrańarles el sentido, que no se lo sacara ni las entendiera el mesmo Aristóteles, si resucitara para solo ello" (Quijote I, 1). Peor aún es la otra referencia directa que existe del Estagirita, puesto que en uno de los cuentos del Quijote se nos narra la historia de una dama enamorada de un fraile soez, bajito e idiota; alguien le hizo notar a la dama la baja condición de su amante, a lo que contestó esta: "Vuestra merced, señor mío, está muy engańado y piensa muy a lo antiguo, si piensa que yo he escogido mal en fulano por idiota que le parece; pues para lo que yo le quiero, tanta filosofía sabe y más que Aristóteles" (Quijote, I, 25).

Las palabras propias del vocabulario filosófico en Cervantes no evidencian un uso específicamente técnico de las mismas. Por ejemplo, con la palabra "metafísica", bien conocido es el diálogo entre Babieca y Rocinante, en las poesías introductorias a la segunda parte del Quijote: "Metafísico estáis. Es que no como". Lo mismo con la palabra "filósofo" que se emplea en un sentido extremadamente vago: "Hízolo así don Quijote, pareciéndole que las razones de Sancho más eran de filósofo que de mentecato" (Quijote, II, 59). 
Con todo esto, no existe motivo para pensar que Cervantes desconociera absolutamente a los tres grandes representantes de la filosofía griega, aunque de ellos sabía lo que cualquier persona de cultura media (y si nos atuviéramos únicamente al texto del Quijote, quizá ni siquiera esto). Lo más asombroso de todo es que ya en el prólogo, el propio Cervantes nos había puesto en guardia acerca de las citas directas de autores o libros famosos; en efecto: esto, más que indicio de pericia filosófica, puede ser indicio de destreza en engarzar textos y citas sin venir a cuento: "En lo de citar en las márgenes los libros y autores de donde sacáredes las sentencias y dichos que pusiéredes en vuestra historia, no hay más sino hacer de manera que venga a pelo algunas sentencias o latines que vos sepáis de memoria, o a lo menos que os cuesten poco trabajo el buscalle" (Quijote, I, Prólogo).

\section{Segundo intento: humanismo y escolástica}

El segundo intento que vamos a realizar para indagar en las fuentes filosóficas de Cervantes tiene que ver con los sistemas filosóficos que pudo conocer debido a su formación. Y aquí nos encontramos con dos resultados matizables: el humanismo y la escolástica, filosofías disueltas en la mentalidad de su época y que, por tanto, se reflejan en sus obras. En el inter formativo de Cervantes, indudablemente estaban estas dos corrientes, y a ellas nos remitiremos ahora.

Aunque la formación académica de Cervantes ha sido una etapa difícil de reconstruir hoy sabemos que seguramente acudió a una escuela de gramática en Sevilla. Las escuelas de gramática eran el segundo nivel de formación, tras pasar unos ańos en las escuelas de primeras letras (a las que también se aluden en el Quijote). ¿Qué se estudiaba en las escuelas de gramática? En dichas instituciones el alumno entraba en contacto con Cicerón, Terencio, Virgilio, 
Ovidio, Séneca, Salustio, Horacio, Quintiliano. Por ejemplo, el opúsculo de Erasmo, De conscribendi epistolis, era habitualmente empleado (Ruiz Berrio, 2004). Si finalmente Cervantes no pasó ningún período formativo en Sevilla sino en cualquier otra ciudad no importa demasiado, porque el ejemplo es suficientemente representativo de las escuelas de gramática de la época y con él nos podemos hacer una idea del mundo humanístico al que accedió Cervantes en dichas escuelas (Quetgles, 2004).

Pero, el humanista que más presente pudo estar en la adolescencia o juventud de Cervantes y al que se han referido numerosos críticos es Juan López de Hoyos, quien regentó una escuela de gramática en Madrid. Atestiguada está la relación entre ambos desde hace tiempo. Menos establecida está la supuesta filiación erasmista de López de Hoyos; filiación establecida tomando como punto fundamental de la argumentación la presencia de algún libro de Erasmo en su Biblioteca personal. Lo que ha sido puesto de relieve recientemente es el poco aprecio que parece guardó Cervantes de su maestro (Alvar, 2014). Alvar ha probado suficientemente que la figura de "el primo" (Quijote, II, 22), en el Quijote, retrata a López de Hoyos, y en él hace una parodia del erudito humanista. Esto no quiere decir que Cervantes no tuviera una evidente tendencia hacia el humanismo; simplemente modera el apresuramiento con que algunos críticos afirman que dicho maestro de gramática es el eslabón perdido entre Cervantes, el humanismo y el erasmismo. El párrafo en el que supuestamente Cervantes retrata a su antiguo maestro humanista, aunque algo extenso, no tiene desperdicio:

En el camino preguntó don Quijote al primo de qué género y calidad eran sus ejercicios, su profesión y estudios, a lo que él respondió que su profesión era ser humanista; sus ejercicios y estudios, componer libros para dar a la estampa, todos de gran provecho y no menos entretenimiento para la república, que el uno se inti- 
tulaba el de las libreas, donde pinta setecientas y tres libreas, con sus colores, motes y cifras, de donde podían sacar y tomar las que quisiesen en tiempo de fiestas y regocijos los caballeros cortesanos, sin andarlas mendigando de nadie, ni lambicando, como dicen, el cerbelo, por sacarlas conformes a sus deseos e intenciones. - Porque doy al celoso, al desdeñado, al olvidado y al ausente las que les convienen, que les vendrán más justas que pecadoras. Otro libro tengo también, a quien he de llamar Metamorfóseos, o Ovidio español, de invención nueva y rara, porque en él, imitando a Ovidio a lo burlesco, pinto quién fue la Giralda de Sevilla y el Ángel de la Madalena, quién el Caño de Vecinguerra de Córdoba, quiénes los Toros de Guisando, la Sierra Morena, las fuentes de Leganitos y Lavapiés en Madrid, no olvidándome de la del Piojo, de la del Caño Dorado y de la Priora; y esto, con sus alegorías, metáforas y translaciones, de modo que alegran, suspenden y enseñan a un mismo punto. Otro libro tengo, que le llamo Suplemento a Virgilio Polidoro, que trata de la invención de las cosas, que es de grande erudición y estudio, a causa que las cosas que se dejó de decir Polidoro de gran sustancia las averiguo yo y las declaro por gentil estilo. Olvidósele a Virgilio de declararnos quién fue el primero que tuvo catarro en el mundo, y el primero que tomó las unciones para curarse del morbo gálico, y yo lo declaro al pie de la letra, y lo autorizo con más de veinte y cinco autores, porque vea vuesa merced si he trabajado bien y si ha de ser útil el tal libro a todo el mundo [...] —Calle, señor — replicó Sancho—, que a buena fe que si me doy a preguntar y a responder, que no acabe de aquí a mañana. Sí, que para preguntar necedades y responder disparates no he menester yo andar buscando ayuda de vecinos. - Más has dicho, Sancho, de lo que sabes — dijo don Quijote_- que hay algunos que se cansan en saber y averiguar cosas que después de sabidas y averiguadas no importan un ardite al entendimiento ni a la memoria (Quijote, II, 22). 
Contrasta este retrato en cierto modo cruel de su maestro madrileño, y el benévolo retrato que hace en el Coloquio de los perros de las escuelas de los jesuitas en Sevilla. Berganza allí dice:

Quedéme sentado en cuclillas a la puerta del aula, mirando de hito en hito al maestro que en la cátedra leía. No sé qué tiene la virtud, que, con alcanzárseme a mí tan poco o nada della, luego recibí gusto de ver el amor, el término, la solicitud y la industria con que aquellos benditos padres y maestros enseñaban a aquellos niños, enderezando las tiernas varas de su juventud, porque no torciesen ni tomasen mal siniestro en el camino de la virtud, que juntamente con las letras les mostraban. Consideraba cómo los reñían con suavidad, los castigaban con misericordia, los animaban con ejemplos, los incitaban con premios y los sobrellevaban con cordura; y, finalmente, cómo les pintaban la fealdad y horror de los vicios y les dibujaban la hermosura de las virtudes, para que, aborrecidos ellos y amadas ellas, consiguiesen el fin para que fueron criados.

\section{A lo que responde Cipión:}

Yo he oído decir desa bendita gente que para repúblicos del mundo no los hay tan prudentes en todo él, y para guiadores y adalides del camino del cielo, pocos les llegan. Son espejos donde se mira la honestidad, la católica doctrina, la singular prudencia, y, finalmente, la humildad profunda, basa sobre quien se levanta todo el edificio de la bienaventuranza (Coloquio de los perros).

Esta última elogiosa referencia, y la previa invectiva contra el humanismo erudito, nos lleva a pensar que quizá la escolástica, en el nivel rudimentario que se podía aprender en las escuelas de gramática, fuera uno de los posibles trasfondos filosóficos del 
Quijote. Así lo han pensado también otros (Morón Arroyo, 2005: 677-694), obteniendo interesantes resultados de la investigación. Podemos dividir en este bosquejo de la escolástica subyacente al Quijote varios apartados, dedicados a la epistemología, la lógica, la metafísica, la teología racional, la antropología, la ética, la política y la estética.

Cervantes mantiene una concepción de la división de las ciencias propia del currículum escolástico de su época. Cuando don Quijote explica las ciencias en las que debe ser versado un caballero, dice en primer lugar que ha de saber derecho, teología y medicina: las tres principales cátedras de las universidades de la época. Luego, dice, ha de ser astrólogo y matemático (el cuadrivio) y dice también que ha de saber de letras (el trivio). Por último, debe saber filosofía moral y artes mecánicas (Calero, 2012: 31-51).

En la epistemología encontramos varias frases o episodios que nos llevan al fondo escolástico de la formación cervantina, como cuando presenta a la experiencia como madre de las ciencias: "Paréceme, Sancho, que no hay refrán que no sea verdadero, porque todos son sentencias sacadas de la mesma experiencia, madre de las ciencias todas" (Quijote, I, 21). Entre el testimonio ajeno o los razonamientos, está claro que Cervantes concede la máxima credibilidad a los sentidos: en los sobradísimamente conocidos episodios del baciyelmo (Quijote, I, 44), está claro que la verdad allí es la que nos pintan los sentidos, contra el testimonio de los demás (y si el barbero concede que es un yelmo solo lo hace tras pagarle el cura a socapa una conveniente retribución) y a pesar de la lanza con que amenaza don Quijote a quien piense lo contrario. Reducidos dichos episodios a la intención paródica original de Cervantes (y dejando de lado las interesantes pero posteriores interpretaciones filosóficas), la prueba de fuego del conocimiento está en los sentidos. Los mismos sentidos corporales son los que atestiguan que los molinos no son gigantes, ni los rebaños ejércitos. 
En la obra aparecen un par de tópicos interesantes sobre la cuestión de la verdad. El primero es el de "Amicus Plato, sed magis amica veritas" (Quijote, II, 51), que el Quijote aconseja por carta a Sancho cuando este es gobernador de la ínsula. La indisponibilidad de la verdad que no se vende a intereses particulares a la que apunta dicho adagio es signo evidente de la concepción realista de la verdad en la que se mueve Cervantes. Siguiendo un tópico habitual, piensa Cervantes de la verdad que su madre es la historia (Quijote, I, 9), derivación del adagio: La verdad es hija del tiempo. La verdad se relaciona así con el tiempo, no en el sentido de que las verdades cambian con el tiempo, sino en el sentido de que "al final todo se sabe": el tiempo va sacando la verdad a la luz. Frente a interpretaciones esotéricas del Quijote, Cervantes es un realista en el sentido más ingenuo del término (Parker, 1948: 287-305).

Hay en los episodios del Quijote un racionalismo moderado, enemigo de supercherías y falsas creencias, muy propio del pensamiento culto de su época. Recordemos cómo Cervantes desvela el aparente misterio del mono parlante de maese Pedro (Quijote, II, 27), o el de la cabeza parlante en casa de Antonio Moreno (Quijote, II, 62); y desbarata la creencia en los agüeros por boca del simple Sancho, al final de la tercera salida (Quijote, II, 73). Estas pseudociencias, que ya habían sido duramente atacadas por San Agustín en la Ciudad de Dios, y por maestros del tiempo de Cervantes como Pedro Ciruelo en su Reprobación de las supersticiones $y$ hechicerías (1551), entrarían en un capítulo específico dedicado a los prejuicios cognitivos propios de la época de Cervantes y contra los que el manco de Lepanto se sitúa decididamente en contra. "Penetrado de los ideales éticos y psicológicos renacentistas, el hombre se enriquece y se conoce mejor. Gracias a ello se prepara el terreno para que surja el método científico y la ciencia moderna” (Gómez-Menor, 2006). 
En el Quijote también hay referencias a la lógica escolástica. Al canónigo de Toledo le gustaba más leer libros de caballerías que las Súmulas de Cardillo de Villalpando (Quijote, I, 47), tratado de lógica tan famoso en la época que Cervantes conoce, al menos de oídas. Pero sorprende más aún la estructura lógica del discurso con que Lotario intenta disuadir a Anselmo de que él sea el instrumento del que se valga para tentar a su mujer en la novela del curioso impertinente (Quijote, I, 33). Dice Lotario que intentará convencer a Anselmo como los predicadores intentan convencer de la fe a los moros: intentando traerlos por razonamientos "demostrativos y matemáticos” (¿alusión a Ramon Llull?), lo cual nos pone sobre la pista de que Cervantes nos va a deleitar con una pieza maestra de lógica. Primero lo intenta con un dilema: o Anselmo cree que su mujer es honesta o no lo cree; pero si cree que es honesta no tiene sentido tentarla; y si cree que no es honesta la confirmación no le hará más feliz y tampoco vale la pena tentarla; así que es razón concluyente no tentarla. En segundo lugar, señala que las cosas se hacen por Dios, para acrecentar fortuna o ganar fama; pero, descartado el motivo divino, está claro que si sale honrada no ganará más fama ni fortuna y si sale deshonrada las perderá; así que no merece la pena tentarla. En tercer lugar razona que, si ella vence, no la estimará más de lo que la estima ahora, y si no vence la tentación él será un desgraciado; así que, de nuevo, no vale la pena tentarla. Todos estos razonamientos pueden reducirse al esquema lógico del dilema (en notación moderna: [(pvq) $\Lambda$ $(\mathrm{p} \rightarrow \mathrm{r}) \Lambda(\mathrm{q} \rightarrow \mathrm{r})]$ - $\mathrm{r})$. No queremos decir con esto que Cervantes estudiara lógica en las Súmulas de Cardillo o que tuviera un conocimiento académico profundo de esta obra, pero evidentemente cierto hábito con textos argumentativos y cierta destreza en su uso demuestran estos breves ejemplos.

En el Quijote también encontramos afirmaciones de calado metafísico, habituales en la escolástica de la época. Por ejemplo: 
cuando el ama y la sobrina tapian la puerta de la biblioteca, tras la primera salida lo hacen con la convicción de que "quitada la causa cesaría el efecto" (Quijote, I, 7), que es la traducción literal del adagio latino: sublata causa tollitur effectus. Lo mismo sucede cuando Sancho y Quijote hacen planes para convertirse en pastores, y Sancho cae en la cuenta de que no puede dejar suelta a su hija Sanchica entre zagales pastores, por lo que entre otra decena de refranes enristra el de que "Quitada la causa, se quita el pecado" (Quijote, II, 67).

Hay alusiones en el Quijote a uno de los problemas metafísicos más duraderos y persistentes en la tradición occidental, a saber: si es posible que el pasado sea distinto de cómo fue. El tema, ya conocido por la filosofía griega, es tratado por Boecio en la Consolación de la filosofía, analizado por extenso en el tratado de Pier Damiani sobre la omnipotencia de Dios, y Santo Tomás le dedica alguna cuestión específica (Suma, I, q.14, a.13). Había dos posturas contrapuestas en este problema y don Quijote, siguiendo al Aquinate, se inclina a pensar que es imposible cambiar el pasado. Por boca de Dorotea, que defiende su honestidad, dice: "Si como estoy, señor, en tus brazos, estuviera entre los de un león fiero, y el librarme dellos se me asegurara con que hiciera o dijera cosa que fuera en perjuicio de mi honestidad, así fuera posible hacella o decilla como es posible dejar de haber sido lo que fue" (Quijote, I, 28). O en la poesía del hijo del caballero del verde gabán, aparece la siguiente reflexión: "Cosas imposibles pido, / pues volver el tiempo a ser / después que una vez ha sido, / no hay en la tierra poder / que a tanto se haya estendido" (Quijote, II, 18).

Podríamos incluir en este apartado sobre la metafísica de cuño escolástico presente en el Quijote la discusión sobre la naturaleza y el arte. Y es un buen ejemplo porque la inmortal obra de Cervantes representa precisamente el punto de intersección entre lo clásico (donde la naturaleza supera al arte) y lo moderno (donde el arte 
supera a la naturaleza). Discurriendo sobre la vocación de los hijos frente al Caballero del verde gabán, cuyo hijo pretendía ser poeta, dice don Quijote que "el arte no se aventaja a la naturaleza, sino perficiónala" (Quijote, II, 16); es decir: que si uno no nace poeta el arte tampoco lo hará (quod natura non dat, salamantica non praestat, decía también un clásico adagio latino). Pero en la obra aparece la postura contraria cuando, a propósito de un duelo de espadas entre un naturalmente diestro bachiller y un artificialmente teórico licenciado, gana el arte a la naturaleza; o como sentencia cervantes: "La fuerza es vencida del arte" (Quijote, II, 19). La ambigüedad de Cervantes en este tema lo sitúa, como hemos dicho, en la encrucijada entre lo clásico y lo moderno.

Aquí y allá abundan en la obra numerosas distinciones propias de la metafísica escolástica. Por ejemplo la distinción entre virtual y formal (más sutil que la evidente distinción entre materia y forma): "Que el merecimiento de una mujer hermosa y virtuosa a hacer mayores milagros se estiende, $y$, aunque no formalmente, virtualmente tiene en sí encerradas mayores venturas" (Quijote, II, 32). La división entre potencia propincua y potencia remota aparece varias veces: “—Razón tienes, Sancho — dijo don Quijote-, porque un caballero andante, como tenga dos dedos de ventura, está en potencia propincua de ser el mayor señor del mundo" (Quijote, II, 39; también en Iglesias, 1989: 120). O la distinción entre bien útil, honesto y deleitable, que se retrotrae a Aristóteles, pasa por Santo Tomás (Suma, I, q.5, a.6) y seguramente Cervantes leería en los Diálogos de Amor de León Hebreo, donde se le dedican unas nutridas páginas: “-_ $\mathrm{Oh}$ mi señora Dulcinea del Toboso, estremo de toda hermosura, fin y remate de la discreción, archivo del mejor donaire, depósito de la honestidad y, ultimadamente, idea de todo lo provechoso, honesto y deleitable que hay en el mundo!" (Quijote, I, 43). 
Si de la metafísica pasamos a la teología racional, encontraremos numerosos testimonios para avalar el trasfondo escolástico de Cervantes. Por ejemplo, en el librillo de memorias de Cardenio se halla escrito: “... si Amor es dios, es argumento que nada ignora, y es razón muy buena que un dios no sea cruel” (Quijote, I, 23). Entre los consejos que don Quijote da a Sancho, está el de ser misericordioso, porque "aunque los atributos de Dios todos son iguales, más resplandece y campea a nuestro ver el de la misericordia que el de la justicia” (Quijote, II, 42). Hay una definición muy teológicamente adecuada del infierno como lugar donde no hay esperanza (Quijote, I, 25), recordando la inscripción en el dintel del infierno de Dante. O aleccionando don Quijote a Sancho de cómo ama un caballero a su dama, descubre el escudero un paralelismo entre dicho amor y el amor puro que se le debe a Dios (Quijote, I, 31), tema este del amor puro que atraviesa toda la mística y se desatará en polémicas en los siglos posteriores.

La antropología de cuño escolástico está igualmente presente en la obra. Hay, para empezar, una reflexión sobre la transitoriedad de la vida, basada en la concepción cristiana (judía o musulmana) del mundo que se opondría a concepciones cíclicas de la misma. Esto lo pone Cervantes en boca de Cide Hamete, filósofo mahomético, para que se vea que la transitoriedad de esta vida y duración de la eterna es una verdad de razón natural:

Pensar que en esta vida las cosas della han de durar siempre en un estado es pensar en lo escusado, antes parece que ella anda todo en redondo, digo, a la redonda: la primavera sigue al verano, el verano al estío, el estío al otońo, y el otoño al invierno, y el invierno a la primavera, y así torna a andarse el tiempo con esta rueda continua; sola la vida humana corre a su fin ligera más que el viento, sin esperar renovarse si no es en la otra, que no tiene términos que la limiten" (Quijote, II, 53). 
Sorprende la atribución a un filósofo mahomético, cuya connotación inmediata nos lleva a Averroes, quien precisamente afirmaba la eternidad del mundo.

De tradición cristiana también, como base incuestionada de toda la escolástica, aparece la división del hombre en cuerpo y alma, algo que se manifiesta en cualquier lugar del Quijote como por ejemplo la división de los consejos de don Quijote a Sancho, que distingue consejos dirigidos al alma y consejos dirigidos al cuerpo (Quijote, II, 42). Veamos ahora las facultades del hombre, según la tópica escolástica. Aparecen en el Quijote referencias al conocimiento sensorial, como hemos visto en los párrafos dedicados a la epistemología, pero también a la división de los sentidos (que en la escolástica superaban el número de cinco por tener en cuenta los sentidos internos del sentido común, fantasía, estimativa y memoria): "Si Dios me guarda mis siete, o mis cinco sentidos, o los que tengo" (Quijote, II, 5). También están presentes los sentimientos o afectos, especialmente en las repetidas ocasiones en las que se afirma que no están en la mano del hombre los primeros movimientos del ánimo (Quijote, I, 20 y 30, entre otros; véase Hutchinson, 2001: 199-206). La memoria también aparece reflejada numerosas veces en el texto cervantino, ocupando un lugar esencial, puesto que Alonso Quijano el bueno la ha perdido de tanto leer libros de caballería, y sin embargo gracias a ella conserva en el alma la impronta que ha dejado en él su seńora Dulcinea, motivo soberano de sus acciones. Algunos autores sitúan el tratamiento de la memoria que hace Cervantes más en la tradición médica que en la tradición retórica, como era habitual (Egido, 1991: 3-44). Por último, también aparecen referencias constantes al entendimiento y la voluntad, como facultades superiores del ser humano según el tratamiento habitual de la época, cuando doña Dolorida dice narrando su desgraciado caso: "En resolución, él me 
aduló el entendimiento y me rindió la voluntad con no sé qué dijes y brincos que me dio" (Quijote, II, 38).

La voluntad humana no es tal si no va acompañada de la libertad. La libertad era no solo uno de los presupuestos habituales de la antropología escolástica sino que cobra especial relieve en el contexto de la Contrarreforma, puesto que el pensamiento luterano tendía a abolir dicha cualidad (recuérdese el De servo arbitrio). En el Quijote son numerosísimas las alusiones a la libertad del hombre. Una especialmente relevante es cuando habla con los galeotes, a quienes se había privado de libertad; y a estos dice don Quijote, “... bien sé que no hay hechizos en el mundo que puedan mover y forzar la voluntad, como algunos simples piensan, que es libre nuestro albedrío y no hay yerba ni encanto que le fuerce" (Quijote I, 22). En una evidentísima interpretación correctiva que hace Cervantes, muy iluminadora, el disfrazado caballero del bosque le dice a don Quijote que "mi destino, o, por mejor decir, mi elección", le llevaron a enamorarse de Casildea (Quijote II, 14). Además, Cervantes escribe con plena conciencia de que la libertad es algo propio de la antropología cristiana, frente a cosmovisiones distintas en este punto: "Pero la suerte fatal, que, según opinión de los que no tienen lumbre de la verdadera fe, todo lo guía, guisa y compone a su modo..." (Quijote, I, 23, Adición).

La libertad es el fundamento de la ética. La ética de base escolástica está igualmente presente a lo largo de toda la obra. Por ejemplo, Cardenio relatando su desgracia, habla de cómo los pastores le ponen al alcance la comida, que él por sí mismo no tomaría, y une así los conceptos de conocimiento como previo a la acción, el deseo como motor de la misma, y la voluntad libre como elementos de la acción específicamente humana: la necesidad natural "me da a conocer el mantenimiento y despierta en mí el deseo de apetecerlo y la voluntad de tomarlo" (Quijote, I, 27). La presencia de la ética de Aristóteles en la obra es notoria y ha sido amplia- 
mente analizada: los bienes de naturaleza y de fortuna, la amistad o la teoría de las virtudes. Por ejemplo, la distinción entre bienes de naturaleza y bienes de fortuna aparece en numerosas ocasiones: "Preguntóle don Quijote que cuántos hijos tenía, y díjole que una de las cosas en que ponían el sumo bien los antiguos filósofos, que carecieron del verdadero conocimiento de Dios, fue en los bienes de la naturaleza, en los de la fortuna, en tener muchos amigos y en tener muchos y buenos hijos" (Quijote, II, 16). La amistad es otro de los tópicos aristotélicos que recorre la obra cervantina. Véase este de Anselmo y Lotario, que nos recuerda la igualdad que debe haber entre dos amigos como condición necesaria para que la amistad pueda ser verdadera: "Eran solteros, mozos de una misma edad y de unas mismas costumbres, todo lo cual era bastante causa a que los dos con recíproca amistad se correspondiesen" (Quijote, I, 33).

Pero si hay algún resabio aristotélico-escolástico en el Quijote es la teoría de la virtud (Sanzol, 2012: 157-185). En numerosas ocasiones nos recuerda Cervantes que la virtud es un término medio entre dos extremos (exceso y defecto); y que, puesto que la media no es matemática, se acerca más a la virtud el que se excede que el que no llega. Don Quijote es el prototipo de valiente con inclinación a la temeridad, que se contrapone a la figura del cobarde Sancho que en varias ocasiones huye de la pelea. Don Quijote es casto en el amor frente a los requiebros de Altisidora y sobrio en el comer y beber, inclinándose más por el lado del exceso (macilento) que del defecto; y esto se contrapone a la glotonería de Sancho o la intemperancia con las mujeres que manifiestan en diversas ocasiones los arrieros (el caso de Maritornes o uno de los casos juzgados por Sancho en su ínsula); ejemplos todos ellos que apuntan a la virtud de la templanza. Don Quijote es prudente, al menos cuando de discurrir se trata, porque cuantos le conocen le llaman discreto; pero va más allá en el conocimiento de la prudencia, y nos desvela 
que conoce también sus partes (que los escolásticos distinguían en integrales, subjetivas, potenciales): "Pero, porque sé que una de las partes de la prudencia es que lo que se puede hacer por bien no se haga por mal, quiero rogar a estos señores guardianes y comisario sean servidos de desataros y dejaros ir en paz..." (Quijote, I, 22). Por último también encontramos la virtud de la justica y sus tipos: remedar la injusticia y el deseo de dar a cada uno lo suyo es lo que mueve a don Quijote en sus salidas (Juan Haldudo, la cuerda de galeotes, etc.); y encontramos a un bandolero catalán que reparte entre sus ladrones los bienes robados con exquisita justicia distributiva, uno de los tres tipos de justicia según la tópica escolástica, como hace notar el discreto don Quijote (Quijote, II, 60).

También encontramos rastros de filosofía política que reflejan las disputas de la época. La licitud moral de defenderse a uno mismo, sancionada por leyes divinas y humanas, la conoce incluso el simple Sancho (Quijote, I, 8). Y de ahí a la famosa cuestión de los títulos de la guerra justa que resuelve don Quijote diciendo que tales causas justas de la guerra son:

la primera, por defender la fe católica; la segunda, por defender su vida, que es de ley natural y divina; la tercera, en defensa de su honra, de su familia y hacienda; la cuarta, en servicio de su rey en la guerra justa; y si le quisiéremos ańadir la quinta, que se puede contar por segunda, es en defensa de su patria. A estas cinco causas, como capitales, se pueden agregar algunas otras que sean justas y razonables y que obliguen a tomar las armas, pero tomarlas por niñerías y por cosas que antes son de risa y pasatiempo que de afrenta, parece que quien las toma carece de todo razonable discurso; cuanto más que el tomar venganza injusta, que justa no puede haber alguna que lo sea, va derechamente contra la santa ley que profesamos, en la cual se nos manda que hagamos bien a 
nuestros enemigos y que amemos a los que nos aborrecen (Quijote, II, 27).

En el diálogo del cura del pueblo con el canónigo de Toledo, al final de la segunda salida, mientras el pobre don Quijote está enjaulado, se nos presentan las líneas maestras de la teoría estética de Cervantes, poco alejada de Aristóteles. Aunque se ha hecho notar que la obra de Cervantes desborda en sí los planteamientos clásicos, cuando hace teoría estética de modo consciente se mantiene bastante fiel a los preceptos aristotélicos (porque una cosa es lo que se hace y otra lo que se dice). Además de la formación humanística y escolástica a un nivel rudimentario de Cervantes, en la estética sí que conocemos la obra a través de la cual le llegó a nuestro autor la mayor parte de la preceptiva literaria de su tiempo: la Philosophia Antigua Poética de El Pinciano. Pero entonces nos movemos ya en lo que hemos llamado el tercer intento por establecer las fuentes de los filósofos y sistemas que están operando en la base de la concepción del mundo que alientan en el Quijote.

\section{Tercer intento: los filósofos de la época}

Las influencias que hasta aquí se han expuesto está claro que no solo le vendrían a Cervantes de sus años de formación, sino que provendrían también de las lecturas que hizo como voraz lector. El tercer intento que seguiremos para rastrear las influencias filosóficas de Cervantes, como se ha indicado, consistirá en asomarnos a la biblioteca de Cervantes para ver qué libros concretos pudieron fecundar su mente. El primero que intentó algo parecido, con la maestría y estilo que le caracterizaba, fue Menéndez Pelayo en un artículo dedicado a la cultura literaria de Cervantes (Menéndez Pelayo, 1941: 323-356). Pero este inicial intento decimonónico se vio ampliamente superado hace unos años por la reconstrucción que 
Eisenberg llevó a cabo de una hipotética biblioteca cervantina, en la que reúne los títulos de los libros a los que con mayor seguridad tuvo acceso y llegó a leer, al menos en parte, Cervantes (Eisenberg, 2002). Repasando la extensa lista de Eisenberg, y centrándonos en aquellos que pudiera ser de carácter más filosófico (menguada parte de la vasta biblioteca, como se imaginará el lector), podríamos dividir las influencias en filosofía del amor, filosofía moral y política, filosofía estética, filosofía popular o paremiología y misceláneas. El intento de sistematización que proponemos, obviamente, ni es excluyente ni está libre de solapamientos.

La filosofía del amor de Cervantes ha sido estudiada en numerosas ocasiones. El amor es algo que atraviesa toda la gran novela cervantina. El amor es el motor del poeta, por ello cuando el Quijote es vencido y hace planes con Sancho para convertirse en el pastor Quijotiz dice que les dará “Apolo versos, el amor conceptos..." (Quijote, II, 67). El amor es el primer motor de la vida de un caballero, "porque el caballero andante sin amores era árbol sin hojas y sin fruto y cuerpo sin alma" (Quijote I, 1); y a modo de primer motor aristotélico, no mueve empujando, sino atrayendo.

La fuente más evidente de la que Cervantes bebe estos conceptos son los Diálogos de amor, de León Hebreo (publicados en italiano 1535 y pronto traducidos al castellano, aunque Cervantes conocía el italiano). En el prólogo al Quijote se cita a León Hebreo: "Si tratáredes de amores, con dos onzas que sepáis de la lengua toscana, toparéis con León Hebreo que os hincha las medidas" (Quijote, I, Prólogo). Esta auténtica enciclopedia del amor dialogada escrita por un judío que tuvo que huir de España trata de la naturaleza del amor, su universalidad y su origen (parece que es una obra incompleta porque anuncia que falta tratar de los efectos del amor sin cumplirlo). Allí se distinguen los objetos del amor, se trata del bien útil, honesto y deleitable, y se discute si el amor nace de la carencia o de la plenitud. Contiene además una 
interesantísima concepción de la poesía antigua según la cual los poetas que narraron los mitos griegos escondieron en sus obras la descripción científica del universo y del hombre. En ella se nos explica que el Sol es el bien y la inteligencia del Universo, la Luna es como el alma del hombre, mientras que el cuerpo es la Tierra. La Luna-Alma, pues, es el centro que está ya bańado por la luz del Sol-Bien, ya oscurecido por la sombra-Tierra.

Toda esta tradición, evidentemente, procede de Platón, con mezclas de Aristóteles, Maimónides, Santo Tomás, la tradición hermética, etc., tal como fue enseńada en la Italia del Renacimiento con la que Cervantes, recordemos, entró en contacto durante su estancia en Roma. Allí pudo conocer y leer seguramente Gli Asolani (1530), los diálogos de amor de Pietro Bembo, el maestro de la prosa italiana. El primero de estos diálogos trata las malas consecuencias que nos vienen por culpa del amor, mientras que en el segundo diálogo se habla de sus beneficios. Parece que para Bembo el auténtico amor es el platónico, que contempla desinteresadamente la belleza, y a esto se le une el ideal ascético cristiano. Italiano es también el Libro di natura di amore (1525), de Mario Equicola que Cervantes leyó según las pesquisas de Eisenberg. También conoció los Diálogos de amor (1593) de Damasio de Frías y Balboa, en los que, como suele ocurrir en todos estos diálogos, el amante se queja de que la amada no le corresponde. En ellos se trata de la mudable condición de los amantes, la esperanza como sustento del amor, los impedimentos del mismo (ausencia, muerte, casamiento), los tipos (espiritual, bestial y mixto), y el desdén como único mal de amor no curable.

Los Diez libros de fortuna de amor (1573), del poeta y soldado sardo Antonio de lo Frasso, se salvan del expurgo que hacen el cura y el barbero en la biblioteca de don Quijote. Leyendo sus encendidas páginas que cantan el amor, se pregunta uno si lo ridículo del amor platónico no estará más bien en nuestra incapacidad de 
sentir semejante tipo de amor. Léanse si no las subidas expresiones del poeta sardo, de quien bebió Cervantes:

Ay vanas fantasías que tan largas me guiais por el espeso desierto. Ay vivir congojoso y desconcierto que amor me da con tan pesadas cargas.

Ay tristes días y noches amargas que me tomasteis el seguro puerto. Ay corazón de lástimas retuerto porque a tanta pena no te adargas. Amor, amor, dime por qué causaste ponerme en tan vano pensamiento y después a lo mejor te descuidaste, pues te amo con extremo sentimiento.

Cuán presto sin razón me olvidaste a mí que por ti muero en tormento (Libro décimo).

Toda esta tradición sobre el amor no está solo presente en la literatura cortés, sino también en la literatura mística y teológica. El propio Cervantes dice en el antedicho prólogo al Quijote: "Y si no queréis andaros por tierras estrañas, en vuestra casa tenéis a Fonseca, Del amor de Dios, donde se cifra todo lo que vos y el más ingenioso acertare a desear en tal materia”. Este tratado del amor de Dios, escrito en dos partes sucesivas, es otro de los estudios más extensos sobre el tema que se hizo en la época (1592-1608), pero desde el punto de vista teológico, con una influencia notable por cierto de los diálogos de amor de León Hebreo. Esta tradición de los tratados sobre el amor de Dios constituiría una sugerencia de investigación muy rica que nos llevaría hasta el siglo xx, con el Tratado del Amor de Dios de Miguel de Unamuno que nunca llegó a 
publicar y que refundió en su obra cumbre, Del sentimiento trágico de la vida (Unamuno, 2005).

Cervantes también accedió a libros de filosofía moral y política. Son abundantes en aquella época los manuales de educación para príncipes. El mayor reflejo de todo este tipo de literatura lo encontramos en los consejos de gobierno que don Quijote da a Sancho antes de partir hacia la ínsula Barataria. Algunos de estos libros estaban escritos por eclesiásticos, y a esta circunstancia se refiere Cervantes, cuando nos habla el eclesiástico que vivía en casa de los duques, y que reprendió severamente a don Quijote. Se trataba de

un grave eclesiástico destos que gobiernan las casas de los príncipes: destos que, como no nacen príncipes, no aciertan a enseñar cómo lo han de ser los que lo son; destos que quieren que la grandeza de los grandes se mida con la estrecheza de sus ánimos; destos que, queriendo mostrar a los que ellos gobiernan a ser limitados, les hacen ser miserables. Destos tales digo que debía de ser el grave religioso que con los duques salió a recebir a don Quijote (Quijote, II, 31).

El libro que con mayor seguridad se ha podido probar que influyó en los conocidos consejos de don Quijote a Sancho es el Perfecto regidor (1586), de Juan de Castilla y Aguayo, publicado 20 ańos antes de que se publicara el Quijote. Dichos consejos son un tratado entero dentro de la obra cervantina. De igual modo que las novelas cortas que incluye la obra pueden estudiarse como piezas literarias aparte, lo mismo con dichos consejos. No hay constancia de que influyera el famosísimo Relox de Príncipes, o Libro Aureo del Emperador Marco Aurelio, de Antonio de Guevara (por ello Eisenberg no la incluye en su biblioteca cervantina), sin embargo es una de las obras de referencia para esta literatura política de la época. 
Obra de corte moralizante puede considerarse la Philosophia cortesana moralizada (1587), de Alonso de Barros: libro curioso que propone una especie de juego de la Oca, con consejos de tipo moral que preludian el barroco gracianesco para sobrevivir en la corte. Otras obras, aunque sean de forma poética, podrían incluirse aquí, como los Triunfos morales (1557), de Francisco de Guzmán, y nombrados por Cervantes en el Canto de Caliope de la Galatea. En estos Triunfos, por ejemplo, encontramos un claro precedente del discurso de las armas y de las letras, tópico habitual de la literatura renacentista:

Digamos una vieja competencia por doctos y guerreros disputada, del arte de las armas y la ciencia cual dellas debe ser la más preciada. Y en ello demos justa la sentencia después de cada parte bien probada, alegue cada uno lo que siente, yo quiero ser entre ellas presidente.

Los Diálogos de fantástica filosofía (1582), de Francisco Miranda Villafañe, que también conoció Cervantes, son tres piezas de filosofía moral. Especialmente interesantes es el segundo diálogo, donde el único tema es la disputa sobre las armas y las letras.

En estas obras poéticas de contenido moralizante que leyó Cervantes podríamos incluir a Andrés Rey de Artieda, con sus Discursos, epistolas y epigramas de Artemidoro (1605); poeta que también cita Cervantes en su viaje al parnaso. Su contenido es variopinto: sobre la vanidad del mundo, los casamientos, el nacimiento de ilustres, sonetos para diversas ocasiones e incluso obras espirituales. Quedémonos con un soneto en el que se canta la resolución 
viril de Julio César, resolución de varón de la que luego hará gala don Quijote:

Aquél varón excelso y peregrino

que de lo bueno tanta parte alcanza, que al Teucro iguala con espada y lanza, y con la pluma al que nació en Arpino.

Llegado que hubo al pueblo de Aremino pero puesto entre miedo y esperanza, de ser vencido, o de tomar venganza del Senador por cuya industria vino, ya que pasar el Rubicón quería, vio que colgaban, solo de un cabello cuantas hazañas hizo hasta aquel día. Quedaba por traidor con emprendellas, volviendo atrás su nombre oscurecía: Al fin se aventuró, y salió con ello.

Cervantes también tendría en su biblioteca la obra de Juan Rufo, Las seiscientas apotegmas (1596), obra de filosofía moral, a caballo entre la miscelánea y la prosa moralizante de casos ejemplarizantes. Hay uno, por ejemplo, sobre la locura de los poetas: "Oyendo cantar algunos romances de poetas enamorados, con relación especial de sus deseos y pensamiento, y aun de sus obras, dijo: Locos están estos hombres, pues se confiesan a gritos". Y otro sobre la locura que produce el amor: "Andaba un caballero mozo y gentilhombre tan perdido por una vieja, que, si no era locura, eran hechizos".

Respecto de la filosofía estética, hay dos claras influencias en Cervantes. La primera es el Arte poética de Horacio, y la segunda la aristotélica y famosa obra del Pinciano. Recordemos que la principal ocasión en la que se habla de estética (aunque las alusiones a 
lo largo de la obra son muy recurrentes) es con ocasión del diálogo que tiene lugar entre el canónigo de Toledo y el cura del pueblo del Quijote, mientras este va enjaulado al final de la segunda salida (Quijote, I, 48). El Arte poética o Epistola a los Pisones, de Horacio, era lectura obligatoria para los estudiantes de gramática en tiempos de Cervantes. Además, antes del Siglo Xvi ya hay dos traducciones al castellano de dicha obra (la de Zapata y la de Vicente Espinel). Menéndez Pelayo en el Siglo XIX recogió con maestría los testimonios bibliográficos de las traducciones horacianas en España (Menéndez Pelayo, 1885).

Pero si hay un libro de estética que sirviera de referencia a Cervantes, y al que todos aluden, este es sin duda la Philosophia antigua poética (1596), del Pinciano. La obra es un delicioso diálogo de preceptiva literaria de corte estrictamente aristotélico. La primera epístola es sobre la felicidad, y resume estupendamente la antropología renacentista de base aristotélica. Luego explica la esencia de la poesía, la fábula (donde distingue la fábula de los episodios, tal como hace Cervantes en el Quijote), el lenguaje poético, los metros, etc. Luego va repasando los distintos géneros literarios siguiendo y discutiendo libremente a Aristóteles: es siempre el punto de partida desde donde se discute. Está muy presente en la obra el problema de la verosimilitud, que en la poesía de ficción se aplica explicando que lo verosímil en ella no es lo narrado sino los afectos suscitados. Es interesante observar cómo el Quijote es, en cierto sentido, una obra de arte total porque engloba todos los géneros: Tragedia, Comedia, Ditirámbica (lírica) y Heróica. El Pinciano también explica los seis géneros menores y habla hasta de los actores del teatro y cómo ha de ser su dicción y gesticulación.

El uso de refranes por parte de Sancho es cuestión que sorprende a cualquiera que se aproxime a la inmortal obra de Cervantes. "-Los refranes de Sancho Panza — dijo la duquesa—, puesto que son más que los del Comendador Griego, no por eso son en menos 
de estimar, por la brevedad de las sentencias. De mí sé decir que me dan más gusto que otros, aunque sean mejor traídos y con más sazón acomodados" (Quijote, II, 34). Los refranes encierran sentido común, verdad extraída de la experiencia, por ello conviene detenerse también en la paremiología y en las fuentes que Cervantes pudo haber empleado para ello. Distinguimos obras paremiológicas cultas, populares y mixtas.

En la paremiología culta que conoce y lee Cervantes están los Dísticos de Verino y los Dísticos de Catón. Dice la duquesa: "Todo cuanto aquí ha dicho el buen Sancho (...) son sentencias catonianas, o por lo menos sacadas de las mismas entrańas del mismo Micael Verino, florentibus occidit annis..." (Quijote, II, 33). Michele Verino fue un niño italiano de salud quebradiza que murió joven pero que dejó escritos unos dísticos en latín que en la época de Cervantes se usaban habitualmente en las escuelas (Verino, 1478). La duquesa habla de las "sentencias catonianas" de Sancho, y Sancho contando el cuento de la pastora Torralba, cita a "Catón Zonzorino", en clara y burlona alusión cervantina a Catón Censorino (Quijote, I, 20). Aunque en realidad el autor de los dísticos de Catón, conocidos por Cervantes y comentados ampliamente en el Renacimiento (Catón, 1997) no eran de Catón el Censor.

Aunque la reconstrucción de la biblioteca cervantina que efectúa Eisenberg no trae ejemplos de paremiología popular o refraneros, podemos poner con toda seguridad dos que Cervantes conocía. La propia duquesa, como hemos visto, dice que los refranes de Sancho son más que los del Comendador griego. ¿Quién es? Se trata de Hernán Núñez, autor de una amplísima recopilación de refranes sin glosa (1555). Pero más interesantes aún y seguramente conocida por Cervantes, dado su evidente interés por el refranero y la fecha de publicación, es la Filosofía vulgar (1568), de Juan de Mal Lara, que contiene cientos de refranes glosados. La práctica totalidad de los refranes que usa Sancho en sus discursos están 
presentes en estos refraneros más que populares, a juzgar por la extensión de las obras.

Podríamos incluir aquí una obra sapiencial, en la línea de la literatura sapiencial bíblica, escrita por Alonso de Barros y titulada Proverbios morales (1598), título que recuerda larga tradición en España de esta literatura donde descuella dom Sem Tob. Se trataría de una obra que combina la sabiduría popular y culta en una original síntesis. Se recogen cientos de proverbios en torno al desengaño y la experiencia. Véase un ejemplo:

Aunque si yo no me engaño

todos jugamos a un juego;

y un mismo desasosiego

padecemos sin reposo.

Pues no tengo por dichoso

al que el vulgo se lo llama,

ni por verdadera fama

la voz de solos amigos.

$\mathrm{Ni}$ por fieles testigos

los que son apasionados.

$\mathrm{Ni}$ tampoco por honrados

los que no son virtuosos.

$\mathrm{Ni}$ a los que son envidiosos

por vecinos de codicia.

$\mathrm{Ni}$ pienso que hará justicia

el que no tiene conciencia,

ni al que le falta experiencia

tendré por buen abogado [...].

En este viaje a las fuentes filosóficas de Cervantes, en donde aparece tanta literatura secundaria no podíamos dejar de lado las misceláneas. Estos curiosos libros, anecdotarios que precedieron 
sin duda la aparición de los periódicos, abundaban en la biblioteca cervantina. El más conocido sin duda, por la fama que tuvo en su tiempo y por la influencia que ejerció en Cervantes, son las Epistolas familiares (1539-1541) del Obispo de Mondoñedo, Fray Antonio de Guevara. A sus obras nos recomienda Cervantes acudir si necesitamos embellecer nuestros escritos con citas y anécdotas curiosas: "si de mujeres rameras, ahí está el Obispo de Mondoñedo, que os prestará a Lamia, Laida y Flora, cuya anotación os dará gran crédito". Estas epístolas son un claro precedente de los ensayos de Montaigne o Feijóo, aunque no llegan a tener ni la maestría ni la sagacidad crítica del benedictino de Samos. En estas epístolas se tratan temas habitualmente cervantinos, tales como el buen caballero, los casamientos, la importancia del linaje si se tiene, y si no se tiene hay que iniciar un nuevo linaje siendo uno mismo virtuoso. Encontramos en estas epístolas usos de algunas palabras cuyo sentido se discute en el Quijote (tales como homecillo y regoldar) que seguramente Cervantes toma de Guevara. El título de alguna de las cartas de Guevara recuerda sospechosamente el irónico título de algún capítulo del Quijote.

En estas obras misceláneas se trataba de todo. El mismo Plinio en su Historia natural había adelantado algo de este género. De Pero Mexía, en su Silva de varia lección (1540) toma Cervantes la idea de que el hombre ha aprendido de los animales algunas técnicas:

Y no le parezca a alguno que anduvo el autor algo fuera de camino en haber comparado la amistad destos animales a la de los hombres, que de las bestias han recebido muchos advertimientos los hombres y aprendido muchas cosas de importancia, como son, de las cigüeñas, el cristel; de los perros, el vómito y el agradecimiento; de las grullas, la vigilancia; de las hormigas, la providencia; de los elefantes, la honestidad, y la lealtad, del caballo" (Quijote, II, 12). 
De este autor, Pero Mexía, también conoció Cervantes unos Coloquios o diálogos, con añadido de Isócrates, filósofo (1551).

Una de las misceláneas más famosas del Renacimiento es la de Antonio de Torquemada, titulada Jardín de flores curiosas (1570). Indudablemente la conoció Cervantes, y en el Quijote nos da una buena idea del contenido del mismo: “—Este es —respondió el barbero- Don Olivante de Laura. —El autor de ese libro — dijo el cura- fue el mesmo que compuso a Jardín de flores, y en verdad que no sepa determinar cuál de los dos libros es más verdadero o, por decir mejor, menos mentiroso; solo sé decir que este irá al corral, por disparatado y arrogante" (Quijote, I, 6). Sin embargo, al parecer el libro influyó en la topografía que configura la novela de los trabajos de Persiles y Segismunda.

En la Biblioteca de Cervantes aún nos quedaría por ojear la traducción del gran Andrés Laguna de la Materia médica de Dioscórides, el Diálogo entre la verdad y la lisonja, de Cristóbal de Castillejo, las obras de San Agustín como La ciudad de Dios o Las confesiones, la Censura de la locura humana y ecelencias de ella, de Hierónimo de Mondragón, el Discurso del amparo de los legitimos pobres y reducción de los fingidos, de Cristóbal Pérez de Herrera, los Ocho libros de los inventores de todas las cosas, de Virgilio Polidoro, o los Discursos consolatorios sobre la muerte, de Francisco Márquez Torres. Pero lo cierto es que, de autores filósofos propiamente dichos o no los conoce (como es el caso del Tostado, cuyo nombre solo recuerda como ejemplo de escritor prolífico) o no se ve la influencia directa de ideas (como es el caso de San Agustín, que si lo leyó, como supone Eisenberg, al menos en el Quijote no se aprecia influencia directa). 


\section{Conclusiones}

Tras este largo recorrido únicamente queda recoger los resultados, aunque nada de lo que aquí se diga suplirá la lectura directa de los textos que conforman el universo mental de Cervantes a la hora de componer el Quijote. Hay que volver de nuevo al texto como criterio máximo de interpretación. El ejercicio de profundización en el texto mismo nos abre a la comprensión de la obra, los propósitos de su creador o las características de su tiempo, y posibilita ir más allá del texto mismo para que sus posibilidades fecunden nuestra realidad. Buscamos entender el Quijote para entendernos mejor; y entendiéndonos, vivir mejor.

De lo dicho hasta aquí se desprende que no se puede acudir al texto con ideas demasiado preconcebidas (porque ciertos prejuicios son inevitables y hasta saludables), en el sentido de que intentemos justificar con el texto lo que hoy en día pensamos de problemas políticos, morales o filosóficos. Buscando testimonios directos de filósofos en el Quijote, hemos encontrado en el primer intento que no hay influencia directa de ningún clásico: Cervantes no leía filosofía académica ni parecía que le interesara especialmente. Hija de su tiempo, la formación de Cervantes se mueve entre el humanismo (al que Cervantes más bien parece despreciar en su forma erudita, recuérdese la figura del "primo") y la escolástica como marco conceptual de fondo, como hemos mostrado en el segundo intento. Ahora bien, tanto el humanismo como la escolástica presentes en su obra no están directamente asimilados de los grandes autores (posiblemente por la falta de educación superior en Cervantes) sino que sus ideas están indirectamente tomadas de la filosofía disuelta que flotaba en el ambiente de las obras con las que trató, tal como hemos visto en el tercer intento.

Que el Quijote no sea una obra filosófica y que la filosofía de su época presente en él sea más bien un trasfondo o barniz es causa 
de que nos sorprenda aún con mayor fuerza la cantidad de "filosofía” que ha emanado de la inmortal obra. Borges decía que un clásico es un libro que nosotros decidimos tomar como modelo (1952); cabría parafrasear concluyendo que una obra será filosófica siempre que la leamos con intención filosófica. Su valor no solo depende de quién la hizo, ni las raíces en las que bebió para ello, sino lo que nosotros hacemos de ello. Pero ninguno de estos tres momentos (presente, pasado, futuro) se puede obviar si queremos seguir hablando con sentido acerca de Cervantes y su imperecedero Quijote.

\section{Bibliografía}

Alvar Ezquerra, A., 2014, Un maestro en tiempos de Felipe II. Juan López de Hoyos y la enseñanza humanista en el siglo XVI, La esfera de los libros, Madrid.

Barros, Alonso de, 1587, Philosophia cortesana moralizada, Viuda de Alonso López, Madrid.

, 1598, Proverbios morales, Luis Sánchez, Madrid.

Bembo, Pietro, 1961, Gli Asolani (primera edición circa 1530), en Opere Volgare, Sansoni, Florencia

Borges, Jorge Luis, 1952, "Sobre los clásicos”, en Otras inquisiciones, Sur, Buenos Aires.

Calero, Francisco, 2012, "Las disciplinas universitarias en el Quijote o 'siendo de toda imposibilidad imposible", Historia de la Educación: Revista Interuniversitaria, núm. 31, págs. 31-51.

Castilla y Aguayo, Juan de, 1586, El perfecto regidor, Cornelio Bonardo, Salamanca.

Catón, 1997, Los disticos de Catón comentados por Erasmo de Rotterdam, A. García Masegosa (ed.), Universidad de Vigo, Vigo. 
Cervantes, Miguel de, 1998, Don Quijote de la Mancha, Edición del Instituto Cervantes, Madrid.

, S/a, Coloquio de los perros. Disponible en: www.cervantesvirtual.com

Ciruelo, Pedro, 1511, Reprobación de las supersticiones y hechicerias, Imprenta de Guillermo de Millis, Medina del Campo.

Eisenberg, Daniel, 2002, La biblioteca de Cervantes. Una reconstrucción, versión preliminar.

Egido, Aurora, 1991, "La memoria y el Quijote", Cervantes: Bulletin of the Cervantes Society of America, vol. 11, núm. 1, pp. $3-44$.

Equicola, Mario, 1525, Libro di natura di amore, Venecia.

Estella, Diego de, 1775, Tratado de la vanidad del mundo, edición original de 1574, Imprenta de Pedro Marín, Madrid.

Fraso, Antonio de lo, 1573, Los diez libros de Fortuna d'amor, Imprenta de Pedro Malo, Barcelona.

Frías y Balboa, Damasio, 1593, Diálogos de Amor, Burgos.

Fonseca, Cristóbal de, 1592, Tratado del amor de Dios, Salamanca.

Gadamer, Hans-Georg, 1999, Verdad y método, Sígueme, Salamanca.

Gómez-Menor Fuentes, José Carlos, 2006, "La filosofía en Cervantes", en Homenaje académico al Quijote en el IV Centenario de su publicación, Real Academia de Bellas Artes y Ciencias Históricas de Toledo, Toledo, pp. 97-101.

Guevara, Fray Antonio de, 1950-1952, Epistolas Familiares (edición original 1539-1541), Real Academia Española, Madrid.

Guzmán, Francisco de, 1557, Triunphos morales, Amberes.

Hebreo, León, 2002, Diálogos de Amor, primera edición de 1535, Alianza, Madrid. 
Heidegger, Martin, 2009, Ser y tiempo, Trotta, Barcelona.

Hutchinson, Steven, 2001, "Los primeros movimientos no son en mano del hombre. Retórica de la emoción en el Quijote", en Cervantes en Italia, A. Villar (ed.), Asociación de Cervantistas, Palma de Mallorca, pp. 199-206.

Jofré, Manuel, 2016, Cuatrocientos años de Don Quijote, Mago Editores, Santiago de Chile.

Kundera, Milan, 1987, El arte de la novela, Tusquets, Barcelona.

Levinás, Emmanuel, 2000, La huella del otro, Taurus, Madrid.

López, Alonso [El Pinciano], 1953, Philosophia antigua poética, edición original de 1596, Consejo Superior de Investigaciones Científicas, Madrid.

López Calle, José Antonio, 2013, "Los krausistas y la filosofía del Quijote”, El Catoblepas, núm. 136, junio, p. 6.

Mal Lara, Juan de, 1568, Filosofía vulgar, Hernando Díaz, Sevilla. Menéndez Pelayo, Marcelino, 1885, Horacio en España: solaces bibliográficos, Imprenta de A. Pérez Dubrull, Madrid.

, 1941, "Cultura literaria de Miguel de Cervantes y elaboración del Quijote", en Obras Completas, Estudios y discursos de critica histórica y literaria, Consejo Superior de Investigaciones Científicas, Santander, pp. 323-356.

Mexía, Pero, 1551, Coloquios o diálogo con añadido de Isócrates, philósopho.

Mexía, Pero, 1992, Silva de varia lección, edición original de 1540, Institución Fernando el Católico, Zaragoza.

Miranda Villafañe, Francisco, 1582, Diálogos de la phantástica philosophía, Herederos de Matías Gast, Salamanca.

Morón Arroyo, Ciriaco, 2005, "El Quijote, filosofía, teología, obra de arte", Príncipe de Viana, año 66, núm. 236, pp. 677-694. 
Muñoz Iglesias, Salvador, 1989, Lo religioso en el Quijote, Estudio teológico San Ildefonso, Toledo.

Nuñez de Toledo, Hernán [El comendador griego], 2001, Refranes de la lengua castellana, primera edición de 1555, Guillermo Blázquez, Madrid.

Parker, Alexander, 1948, "El concepto de verdad en el Quijote", Revista de Filología Española, núm. 32, pp. 287-305.

Popper, Karl, 1980, La lógica de la investigación cientifica, Tecnos, Madrid.

Quetgles Roca, María Lluisa, 2004, "La educación en el Quijote”, Revista de Educación, núm. extraordinario, pp. 119-137.

Rey de Artieda, Andrés, 1605, Discursos, epistolas y epigramas de Artemidoro, Ángelo Tavanno, Zaragoza.

Ricoeur, Paul, 2017, Hermenéutica, Escritos y conferencias 2, Trotta, Barecelona.

Rubio, David, 1943, La filosofía del Quijote, Losada, Buenos Aires. Rufo, Juan, 1596, Las seiscientas apotegmas, Pedro Rodríguez, Toledo.

Ruiz Berrio, Julio, 2004, "El oficio de maestro en tiempos de Cervantes”, Revista de Educación, núm. extraordinario, pp. 11-26.

Ruiz Fernández, Jesús, 2014, "El socratismo cristiano en el Quijote", Ingenium: Revista electrónica de pensamiento moderno y metodología en historia de las ideas, núm. 8, pp. 93-113.

Sanzol, Francisco Javier, 2012, "Las virtudes en el Quijote: una aproximación”, Cuadernos de Estudios Manchegos, núm. 37, pp. 157-185.

Torquemada, Antonio de, 1570, Jardin de flores curiosas, Salamanca.

Unamuno, Miguel de, 1967, El sentimiento trágico de la vida, en Obras Completas, Escelicer, Madrid. 
,2005, Del sentimiento trágico de la vida. Tratado del amor de Dios, Tecnos, Barcelona.

Verino, Michele, 1987, Distichorum liber, edición original de 1478, Conselleria d'Educació y Cultura, Balears. 